\title{
$\mathrm{VII} \mathrm{CINCCI}$
}

VII Colóquio internacional sobre Comércio e Cidade

Fortaleza, 03 a 07 de Novembro de 2020

\section{A dimensão olfativa e o projeto de interiores comerciais: multissensorialidade no ambiente construído}

The olfactory dimension and the design of commercial interiors: multisensory in the built environment

La dimensión olfativa y el diseño de interiores comerciales: multisensorial en el entorno construido

ROMANOS, Paloma; Mestra; Universidade Federal de Juiz de Fora (UFJF)

paloma.romanos@arquitetura.ufjf.br

MENDES, Caroliny; Graduanda; Universidade Federal de Juiz de Fora (UFJF) caroliny.arquitetura@outlook.com

ANGELICA, Larissa; Graduanda; Universidade Federal de Juiz de Fora (UFJF) larissa.angelica@yahoo.com.br

VELLOSO, Isabela Monken; Doutora; Universidade Federal de Juiz de Fora (UFJF) isamonken@uol.com.br

BRAIDA, Frederico; Doutor; Universidade Federal de Juiz de Fora (UFJF)

frederico.braida@ufjf.edu.br

\section{Resumo}

Este artigo aborda a dimensão olfativa como componente do projeto de interiores comerciais. Embora os odores nos pontos de venda sejam recorrentemente tratados pelo marketing, como estratégia de uma marca criar sua identidade através dos aromas, eles também compõem uma dimensão do ambiente construído. A questão discutida é: como os odores têm sido (ou podem ser) incorporados como um componente do projeto de interiores? O principal objetivo é evidenciar como os pontos de venda de algumas marcas, sobretudo de varejo de moda, criam espacialidades que se conformam, também, a partir da dimensão olfativa. Para tanto, do ponto de vista metodológico, além da pesquisa bibliográfica, foram selecionadas duas marcas para análise: Le Lis Blanc e Osklen. O que se evidencia é que, para além da primazia da visualidade, os odores podem ser incorporados como uma dimensão dos projetos de interiores que explorem a multissensorialidade, possibilitando a ampliação das experiências dos consumidores.

Palavras-chave: Dimensão olfativa. Projeto de Interiores Comerciais. Multissensorialidade. 


\title{
$\mathrm{VII} \mathrm{CINCCI}$
}

VII Colóquio internacional sobre Comércio e Cidade

Fortaleza, 03 a 07 de Novembro de 2020

\section{The olfactory dimension and the design of commercial interiors: multisensory in the built environment}

\begin{abstract}
This article addresses the olfactory dimension as a component of commercial interior design. Although odors at points of sale are frequently treated by marketing, as a brand strategy to create its identity through aromas, they also make up a dimension of the built environment. The question discussed is: how have odors been (or can be) incorporated as a component of interior design? The main objective is to show how the points of sale of some brands, especially fashion retailers, create spatialities that also conform to the olfactory dimension. Therefore, from the methodological point of view, in addition to the bibliographic research, two brands were selected for analysis: Le Lis Blanc and Osklen. What is evident is that, in addition to the primacy of visuality, odors can be incorporated as a dimension of interior projects that explore multi-sensoriality, enabling the expansion of consumer experiences.
\end{abstract}

Keywords: Olfactory dimension. Commercial Interior Design. Multisensory.

\section{La dimensión olfativa y el diseño de interiores comerciales: multisensorial en el entorno construido}

\section{Resumen}

Este artículo aborda la dimensión olfativa como un componente del diseño interior comercial. Aunque los olores en los puntos de venta son tratados frecuentemente por el marketing, como una estrategia de marca para crear su identidad a través de los aromas, también constituyen una dimensión del entorno construido. La pregunta discutida es: ¿cómo se han incorporado (o se pueden) incorporar los olores como un componente del diseño de interiores? El objetivo principal es mostrar cómo los puntos de venta de algunas marcas, especialmente en el comercio minorista de moda, crean espacios que se ajustan, también, desde la dimensión olfativa. Por lo tanto, desde el punto de vista metodológico, además de la investigación bibliográfica, se seleccionaron dos marcas para el análisis: Le Lis Blanc y Osklen. Lo que es evidente es que, además de la primacía de la visualidad, los olores pueden incorporarse como una dimensión de proyectos interiores que exploran la multisensorialidad, permitiendo la expansión de las experiencias del consumidor.

Palabras clave: Dimensión olfativa. Diseño de interiores comerciales. Multisensorial. 


\section{Introdução}

O mercado exigente da contemporaneidade impulsionou as empresas para que elas atribuíssem mais atenção ao ponto de venda (PDV), a fim de se diferenciarem, pois os consumidores, mesmo adquirindo os produtos de forma virtual, ainda valorizam (ou, pelo menos, valorizavam, até o início da pandemia de Covid-19) a experiência do ambiente de loja e o convívio com as pessoas, vendedores e outros clientes. Logo, segundo Malhotra (2013), um fator importante para o sucesso de varejistas é o cuidado com o desenvolvimento do design de loja, baseado na psicologia do consumidor, disciplina que considera o ser humano e sua percepção do ambiente.

O projeto dos interiores comerciais, ou do PDV, é complexo, conforme evidencia Saddi (2013), e exige um acionamento de inúmeros profissionais. Embora haja uma primazia da visualidade como dimensão projetiva, o ambiente construído afeta todos os sentidos humanos. Portanto, o que se percebe é uma demanda por projetos que sejam verdadeiramente holísticos e que ultrapassem o sentido da visão. É nesse sentido, que enfocamos, neste artigo, a dimensão olfativa.

Os estudos que abordam o tema dos odores e do ambiente, especificamente o ambiente comercial, estão concentrados principalmente no campo do marketing (GULAS; BLOCH, 1995; CANNIFORD; RIACH; HILL, 2017; LINDSTROM, 2005; HENSHAW et al., 2015) e o foco das pesquisas que abordam essa temática tem sido entender o comportamento de compra por meio dos estímulos de odores ambientais. Quando esses estudos são direcionados ao ambiente construído, o conceito de "atmosfera" (KOTLER, 1974) se destaca.

O aroma ambiental, segundo Malhotra (2013, p. 134), é utilizado por várias marcas e, no caso do aroma de assinatura, tem o papel de tornar o PDV único e diferenciado, frente à concorrência. Ainda segundo o autor, "perfumes não somente marcam uma loja, mas também evocam fortes respostas emocionais, como sentir-se mais relaxado, mais animado, ou nostálgico" (MALHOTRA, 2013, p. 134).

De acordo com Velloso (2019, p. 87), o universo da moda, marcado pela noção de visualidade e aparência, também faz uso dos odores, operando com a produção de camadas muito palpáveis de emoções evocadas. Sabendo da influência dos odores sobre as emoções dos consumidores, as empresas criadoras de aromas de assinatura, especialistas em marketing olfativo, desenvolvem as essências de forma congruente com a identidade da marca e o perfil do consumidor.

Dadas essas informações e ao considerá-las no contexto do projeto do ponto de venda, surge a seguinte questão: como os odores têm sido (ou podem ser) incorporados como um componente do projeto de interiores? Ou, ainda: De que modo o projeto de interiores comerciais interage com o projeto da identidade olfativa criada para a marca de moda?

Como se sabe, os aromas, no ambiente construído, possuem, ao menos, duas implicações que se relacionam com o conforto ambiental (ROMANOS, 2020): uma de natureza pragmática e funcional, e outra, estética e simbólica. A primeira tem a ver com as questões da qualidade do ar, de saúde; a segunda, com as questões emocionais, de memória. Portanto, embora essa temática não tenha sido tratada como uma questão de extrema relevância para arquitetos e designers de interiores, não pode ser desprezada por esses profissionais. 
Assim, este artigo tem por objetivo principal evidenciar como os PDV de algumas marcas, sobretudo de varejo de moda, criam espacialidades que se conformam, também, a partir da dimensão olfativa, ressaltando que os aromas se constituem como elemento de projeto do ambiente construído, uma vez que têm a potencialidade de interferir nas experiências dos consumidores nos espaços.

\section{Metodologia}

Do ponto de vista metodológico, pode-se dizer que este artigo é resultado de uma pesquisa de natureza qualitativa e exploratória, tanto teórica quanto empírica, levada a cabo no âmbito do Grupo de Pesquisa INTRA, vinculado à Faculdade de Arquitetura e Urbanismo e ao Programa de Pós-Graduação em Ambiente Construído, da Universidade Federal de Juiz de Fora e conduzida por uma equipe constituída por uma mestranda, duas bolsistas de iniciação científica e dois pesquisadores doutores.

A pesquisa partiu de uma revisão bibliográfica, com coletas de dados científicos realizadas nos anais do $\mathrm{CINCCI}$, nos Periódicos CAPES e em livros especializados. Também foram coletados dados bibliográficos em sites de marcas de moda que se utilizam das técnicas de marketing olfativo e em sites das empresas que desenvolvem os aromas de assinatura, a fim de se compreender as relações entre os ambientes comerciais dessas marcas e o discurso presente em seus aromas exclusivos.

Já a pesquisa empírica se pautou na análise de duas marcas, Le Lis Blanc e Osklen, selecionadas devido à explícita incorporação dos aromas na identidade da marca, com marcante presença nos PDV, mostrando-se relevantes para serem abordadas como objetos exemplares para as discussões propostas na pesquisa.

Assim, tomando os modelos teóricos de Saddi (2013, p. 19 e 224) como referência, porém adotando uma perspectiva do ambiente construído, enfatizamos, neste artigo, os odores como elementos que constituem uma dimensão dos projetos de interiores comerciais.

\section{Odores e o projeto de interiores comerciais}

A utilização de aromas em ambientes comerciais é recorrentemente feita pelo marketing, como estímulos sensoriais, a fim de impactar os consumidores no PDV (MALHOTRA, 2013, p. 133). Canniford, Riach e Hill (2017, p. 240) postulam sobre os aromas do produto e do ambiente, caracterizando o odor do produto responsável pela atração e estimulação dos consumidores para as compras e o odor ambiente por condicionar anexos significativos e duradouros entre consumidores e espaços.

Gulas e Bloch (1995, p. 88) afirmam que o odor é relevante para o consumo e se apresenta no ambiente comercial através do perfume, que está diretamente associado a um objeto encontrado no produto comercializado, ou ele faz parte do ambiente global. Os autores exemplificam o odor introduzido em produtos como o sabão de lavar roupas que tem um papel importante na avaliação e escolha entre os produtos da prateleira do supermercado. Em relação ao odor ambiente, este tem um impacto mais global e influencia as reações do consumidor diante de todos os produtos presentes no PDV, incluindo aqueles produtos que seriam mais difíceis de adicionar fragrâncias artificiais (GULAS; BLOCH, 1995, p. 89). 
O odor ambiental introduzido em ambientes comerciais deve ser congruente com o produto comercializado, com a identidade da marca ou mesmo com o meio ambiente, no caso com o projeto de interiores comerciais, que traduz no espaço da loja a intenção da marca e seu DNA (LEENDERS; SMIDTS; HAJI, 2019, p. 2). Os autores ainda completam afirmando que a incongruência com o ambiente pode, ao invés de atrair, causar repulsa, visto que os consumidores não serão encantados emocionalmente pela marca, e suas escolhas serão estritamente racionais, e assim, se tornam menos propensos a se envolver no processamento cognitivo que as ações de marketing multissensorial buscam.

O nível de intensidade dos odores ambientais também pode causar percepções diferenciadas, como odor agradável e desagradável (LEENDERS; SMIDTS, HAJI, 2019, p. 2). De acordo com Chebat e Michon (2003, p. 531), odores mais intensos tendem a causar reações negativas nas pessoas.

Os aromas de assinatura, odores artificiais desenvolvidos com exclusividade, são utilizados por várias empresas para aumentar a recordação de seu produto ou serviço (MORRIN; KRISHNA; LWIN, 2011, p. 354). O uso de odores para efetivar a memória dos consumidores em relação a um estabelecimento comercial auxilia também no reforço de informações associadas, uma vez que, em um momento futuro, quando o consumidor sentir novamente aquele odor, haverá uma interferência retroativa, ou seja, uma recordação da experiência vivida anteriormente (MORRIN; KRISHNA; LWIN, 2011, p. 355).

Segundo Canniford, Riach e Hill (2017, p. 240), o odor desencadeia recordações não apenas de experiências com as marcas, mas também orienta as respostas afetivas de espaços experienciados em algum momento, além de levar de volta, por meio da memória, a espaços anteriormente encontrados. Isso se dá pelo fato de o olfato ser um sentido que tem ligação direta com o sistema límbico do cérebro, responsável pelo processamento das emoções e memória (MALNIC, 2008).

Para além das questões de marketing, de impulso às compras, as experiências relacionadas com odores podem proporcionar vivências mais imersivas para os clientes, tornando o momento no ambiente comercial mais marcante e memorável (HENSHAW et al., 2015, p. 155). De acordo com Pine e Gilmore (1998, p. 1), a experiência nas lojas é uma oferta tão real quanto qualquer outro serviço, bem ou mercadoria e as empresas devem projetar experiências envolventes que gerem satisfação aos clientes, pois experiências, como produtos e serviços, precisam atender a uma necessidade do cliente. Assim, o projeto do ambiente pode encenar uma experiência aos clientes por meio de um envolvimento sensorial que vai além do sentido da visão e audição, elevando o sentido do olfato para um destaque maior.

A gestão dos odores em ambientes de varejo e serviços é uma ferramenta de diferenciação das marcas, produtos e locais, em um mundo em que o campo visual é saturado pela publicidade (CANNIFORD; RIACH; HILL, 2017, p. 240). Odores também diferenciam e segmentam ambientes existentes dentro de um espaço maior, como de um grande magazine, no qual existem odores diferentes para cada setor de produtos, por exemplo, moda feminina, moda masculina, moda praia, entre outros, fazendo com que os consumidores percebam de forma sutil a singularidade existente em cada ambiente dentro de uma mesma loja. Lindstrom (2007, p. 38) destaca que o odor de uma marca deve ser claro e distinto, assim como é elaborado sua imagem e sons, o aroma deve ser "sutil que em alguns casos está tão integrado à marca que as pessoas dificilmente percebem". 
O odor pode ou não ter relação direta com o produto em si, como é o caso singular do aroma de pipoca que é associado a um cinema. Semioticamente, pode-se falar que o aroma de pipoca é um signo do cinema. $O$ cheiro de pipoca "tornou-se tão fortemente ligado ao cinema que se não o sentíssemos, provavelmente teríamos a sensação de que algo estava errado" (LINDSTROM, 2007 , p. 26). Esses estímulos sensoriais desempenham um papel de diferenciação entre um produto e outro, e se inserem na memória de longo prazo e passam a fazer parte do processo de tomada de decisão dos consumidores em ambientes de lojas (LINDSTROM, 2007, p. 27).

Pallasmaa (2011, p. 52) destaca o poder dos odores na evocação de memórias e sentimentos quando cita o "mundo de aromas de uma loja de balas nos faz lembrar da inocência e curiosidade da infância; o odor pungente de uma sapataria nos faz imaginar cavalos, selas e arreios e a emoção de se cavalgar". Portanto, percebe-se que os aromas, de fato, funcionam como signos que permeiam as memórias dos consumidores.

Os psicólogos ambientais Mehrabian e Russel (1974 apud SPANGENBERG, 2006, p. 1282) defendem o efeito do humor sobre a cognição e comportamento das pessoas em um ambiente de compra, quando levantam uma abordagem da psicologia ambiental baseada em estímulo-organismo-resposta, no qual o estímulo poderia ser o aroma inserido na atmosfera da loja; o organismo seriam os consumidores e a resposta seria o julgamento em relação ao ambiente considerado então agradável ou desagradável, e, por consequência, ocasionaria o comportamento de aproximação ou afastamento em relação ao ponto de venda.

Okamoto (2002) define a percepção do ambiente como o resultado da interpretação pessoal dos estímulos externos, por exemplo, os odores ambientais, pois a percepção se relaciona com o espaço perceptivo através de experiências sensoriais, visto que é a partir dos sentidos que os ambientes são percebidos (RHEINGANTZ, 1995). Os odores se manifestam através de aspectos físicos, relativos ao ambiente de loja, pois estão presentes de forma inerente aos espaços; e psicológicos, visto que os odores impactam os indivíduos através de uma experiência multissensorial, podendo inclusive ficar retido na memória pela ligação direta com o sistema límbico, conforme pode ser visto na figura 1. 


\section{ASPECTOS \\ DOS ODORES}

\section{FÍSICOS}

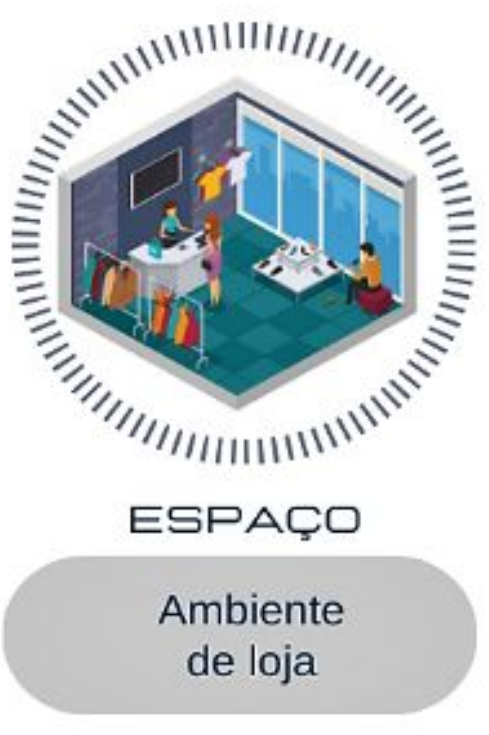

\section{PSICOLÓgICOS}

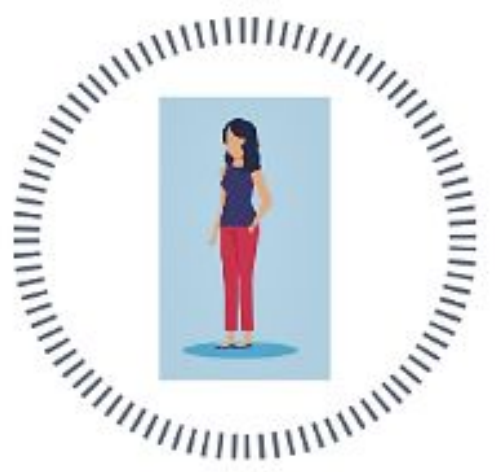

SER HUMANO

Experiência sensorial memorável

Figura 1: Aspectos dos odores

Fonte: Ícones disponibilizados do site Freepik. Elaborado pelos autores, adaptado de ROMANOS (2020).

Uma vez que os seres humanos dependem do ar para sobreviverem, são afetados pelos cheiros durante o tempo todo, haja vista que os cheiros, que são moléculas odoríferas, desprendem-se dos objetos e ficam dispersas no ar, até que penetrem nas narinas e chegam ao bulbo olfatório, sendo identificadas pelos nervos olfatórios que se ligam diretamente ao cérebro e chegam ao sistema límbico, responsável pelas emoções e memória (GUIMARÃES, 2009, p. 18). Em vista disso, Pallasmaa destaca que a "memória mais persistente de um espaço é seu cheiro" (2011, p. 51). Ainda, em relação ao espaço de loja, McGoldrick e Pieros (1998 apud BARBOZA et al., 2010, p. 2) afirmam que "uma atmosfera de loja, quando projetada da maneira certa, pode influenciar favoravelmente a tendência do consumidor em se tornar cliente".

O odor faz parte da ambientação e, segundo Medina (2009), é capaz de provocar profundo bem-estar. $O$ reconhecimento das marcas pelos seus odores ambientais evidencia a importância desse artifício em relação ao "valor emocional da marca e produto, aplicados no ponto-de-venda" (MEDINA, 2009, p. 7). O uso dos odores no ambiente comercial é uma ferramenta do marketing olfativo, que se utiliza da odorização para criar associações entre as marcas e os aromas, despertando interesse e desejo nos consumidores (FLOR; UMEDA, 2008, p. 1) ou, ao menos, ampliando os canais comunicativos na experiência do consumo. 


\section{Os aromas de Le Lis Blanc e Osklen}

A marca Le Lis Blanc, referência nacional em termos de sofisticação, estilo e qualidade em moda, buscou se diferenciar e se fazer autêntica frente ao mercado competitivo, quando recorreu ao desenvolvimento de uma assinatura olfativa que lhe colocava em uma posição muito particular, a essência era única. O discurso da Le Lis Blanc, em relação à identidade da marca, demonstra inocência, delicadeza, sofisticação e feminilidade que a envolve (DIAS, 2017). De acordo com Cecília Borges, consultora de marketing olfativo que participou da elaboração do aroma da Le Lis Blanc juntamente com Irene Lima, da Seivaroma e do perfumista Cláudio Rubino, a criação da identidade olfativa é realmente coerente com o DNA da marca, e expresso no sutil aroma de alecrim, elaborado ao longo de sete meses de imersão na companhia (EXAME, 2017; SEIVAROMA, 2017). Segundo o discurso da empresa SeivAroma, uma das pioneiras em marketing olfativo no Brasil, o produto é "tão marcante que não há quem não chegue em qualquer uma de suas lojas pelo País e não se deixe levar pela sensação refrescante daquele perfume delicioso, aconchegante" (SEIVAROMA, 2017).

O aroma Alecrim "surgiu da necessidade de criar uma identidade única e diferenciada para suas lojas. Algo como uma lembrança olfativa da marca" (DIAS, 2017). A empresa que concebeu a assinatura olfativa da marca relata sua intenção de, com a composição, produzir uma sensação de bem-estar e de alegria para o público-alvo. A essência fez parte de uma minicoleção formada de um home spray, refil de meio litro do home spray (com um funil cromado exclusivo), copos com velas perfumadas, o guest soap (caixa de minis sabonetes para lavabo) e sabonete líquido para as mãos (SEIVAROMA, 2017).

O ambiente do ponto de venda da Le Lis Blanc foi projetado com atmosfera diferenciada, um ar de sofisticação, apresentando-se atraente e acolhedora (DIAS, 2017). A figura 2 mostra o uso de espelhos, vidro e metal dourado que remetem à sofisticação; a feminilidade é vista no mobiliário, como as poltronas e cadeiras em desenho do espaldar com curvas e tecidos nobres. A madeira clara demostra a delicadeza da marca; o piso e teto, em tom off white, lembram o lírio branco, significado de le lis blanc em francês. A iluminação é intimista, assim como os ambientes criados, com sofás amplos um de frente para o outro com mesa de centro, convidativos para uma conversa entre amigas, com um aroma ambiente envolvente. 


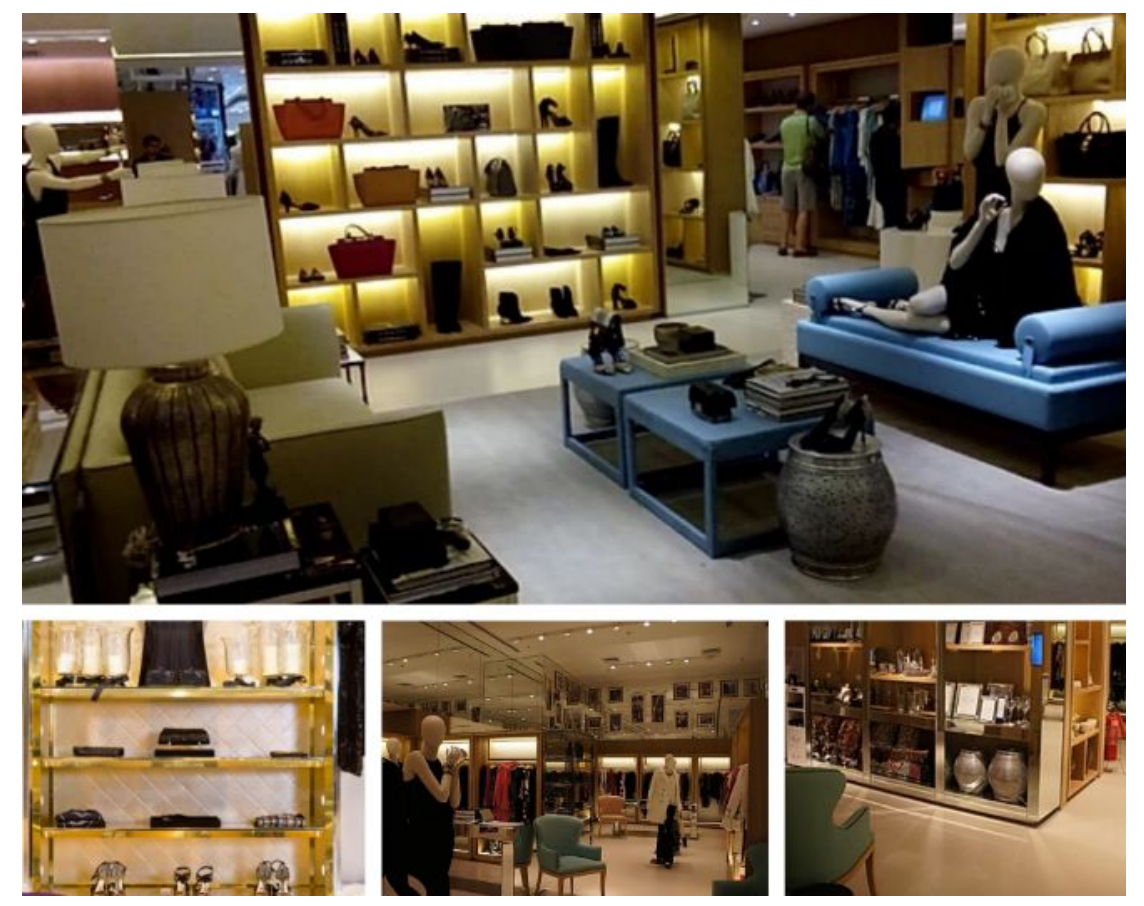

Figura 2: Interior da loja Le Lis Blanc

Fonte: Lavinia [s.d.]; Marques [s.d.]. Montagem dos autores.

Assim como em Le Lis Blanc, a assinatura olfativa de Osklen faz parte de sua identidade. Tecnologia e sustentabilidade são os conceitos abordados pela marca Osklen diretamente nos materiais que compõem as roupas da grife de alma brasileira (FARFETCH, 2018). A moda sustentável da Osklen trabalha com matérias-primas como materiais reciclados e fibras naturais. Em 2006, além de usar as conhecidas estampas que evidenciavam a defesa do meio-ambiente, a empresa incorporou novos materiais sustentáveis como o látex natural da Amazônia e o couro de salmão, tilápia, dourado e pirarucu (FARFETCH, 2018). A Osklen começou por um hobby de Oskar Metsavaht, fundador da marca: a prática de esportes radicais e viagens de aventura. Em uma de suas viagens, ele percebeu a falta de vestuário adequado ao frio extremo para adquirir no Brasil e desenvolveu um "tecido (chamado de Storm Tech System), com membrana interna permeável, que permitia a evaporação do suor, mantendo o corpo seco e aquecido, ideal para prática de esportes de inverno e climas severos" (DIAS, 2006). Foi então que largou a medicina e lançou a marca, desenvolvendo, ao longo, do tempo tecidos com tecnologia e sustentabilidade.

Através do desenvolvimento de uma coleção em 2005, chamada Vento, o perfume utilizado como aromatizante nas lojas da rede foi incorporado ao mix de roupas e sapatos da marca (DIAS, 2006). A essência foi desenvolvida pela mistura do cítrico amadeirado e verde amadeirado, uma "fragrância extremamente marcante e deliciosa" (CHEIRO BOM LOJA, 2016). O odor ambiental, que também é vendido na loja, reporta à natureza, assim como os materiais sustentáveis do mobiliário e das peças de roupas.

O design das lojas Osklen utilizam da madeira reciclada e móveis em madeira de demolição, para associar ao conceito de sustentabilidade, que faz parte da identidade da marca. Elementos esportivos como prancha de snowboard e taco de 
golfe fazem parte da decoração, remetendo ao esporte, que faz parte da história do início da empresa.

"Moda, arte, cultura, design e meio ambiente que compõe a decoração são projetadas por uma equipe do departamento voltado para o design e ambientação, formada por arquitetos, designers, decoradores e vitrinistas da própria OSKLEN" (DIAS, 2006).

A vegetação no interior da loja, a paginação do calçadão de Ipanema aplicado na parede e o revestimento do piso em tonalidade de areia clara faz referência ao meio ambiente, o ambiente natural e a praia, declarando o estilo de vida (lifestyle) que a Osklen argumenta em seu DNA. Dessa forma, o aroma exclusivo, Vento, completa a atmosfera multissensorial que envolve o ponto de venda, conforme mostra a figura 3 .

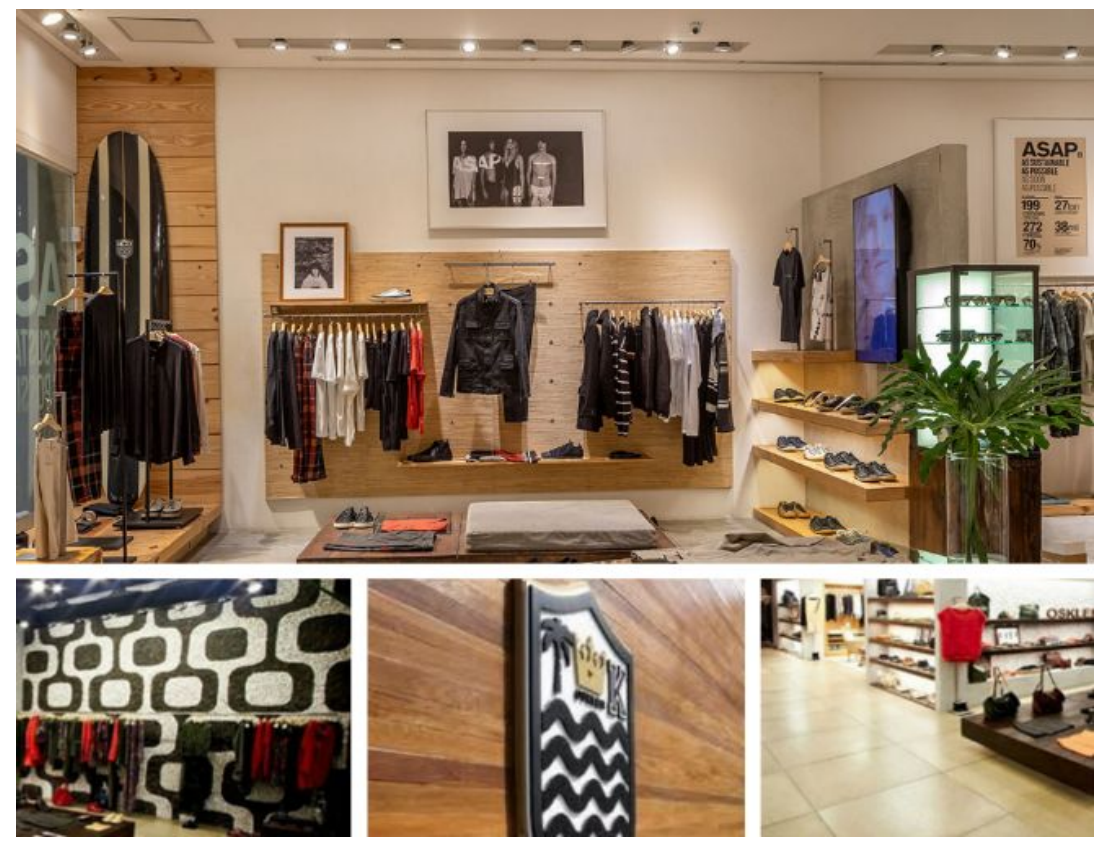

Figura 3: Interior da loja Osklen

Fonte: Girão (2011); Shopping Leblon (2000); Dias (2006). Montagem dos autores.

Embora as imagens não possam despertar, diretamente, nossa percepção olfativa, é praticamente um truísmo afirmar que todas as pessoas que já estiveram nos pontos de venda da Le Lis Branc e/ou da Osklen (e tomaram contato com as fragrâncias supracitadas) têm suas memórias ativadas. Para além das especificidades de cada marca, os que elas possuem em comum é uma assinatura olfativa marcante, que, além de fazer com que essas lojas se destaquem no mercado, potencializam, nos PDV, as experiências multissensoriais.

\section{Multissensorialidade no ambiente construído e o projeto de interiores comerciais}

Quando se tem a oportunidade de estar em um PDV de marcas de moda que possuem uma assinatura olfativa, tais como Le Lis Blanc e Osklen, ou quando se analisa o discurso sobre as experiências dos consumidores nesses espaços, 
constata-se que os odores constituem uma característica intrínseca do ambiente construído, muitas vezes tão percebidos quanto os signos visuais. Os odores compõem as vivências ocorridas no ambiente de loja, causando experiências multissensoriais projetadas, sensações estimuladas, para que o cliente utilize, conscientemente ou não, seus sentidos na percepção do ambiente comercial, para internalizar as mensagens que as marcas querem difundir.

Conforme verificado, inclusive a partir dos exemplos de marcas trazidos neste artigo, quando os odores estão presentes nos interiores comerciais, eles, geralmente, são pensados dentro de uma lógica do marketing olfativo. No entanto, acreditamos que é a partir das experiências já existentes que arquitetos e designers de interiores podem ampliar seu repertório de projeto, tratando o espaço de um ponto de vista mais holístico, porém, por vezes, "não se atentam ao fato de que, para a atmosfera ser percebida pelos consumidores e gerar experiência memorável, um caminho eficaz é projetar com foco nas emoções que perpassam pelos sentidos" (ROMANOS et al., 2020, p. 2).

De qualquer forma, devido às complexidades dos projetos de interiores comerciais, faz-se necessário pontuar que é essencial a formação de uma equipe multidisciplinar, composta por arquitetos, designers, consultores olfativos e de profissionais de marketing, comunicação e merchandising visual, que projete o espaço de forma integrada, para que haja uma congruência efetiva entre a identidade da marca e o ponto de venda.

O que propomos é que todas as dimensões projetuais devam estar devidamente alinhadas no momento de concepção. Pelo que se percebe, inclusive pela literatura(ROMANOS, 2020), é que os profissionais do projeto do ambiente construído não estão acostumados a pensar no odor no momento em que projetam; quando muito, consideram as questões relativas à qualidade do ar interior.

Ainda cabe destacar que, o marketing olfativo, sob o olhar do ambiente construído, não tem como foco exclusivo nas vendas e sim nas possibilidades de proporcionar experiências completas para os usuários nos PDV, visto que, na atualidade, o que se consome em uma loja vai além da materialidade dos produtos.

\section{Considerações finais}

Conforme evidencia a literatura, e a própria observação empírica, os odores inseridos nos PDV proporcionam uma experiência ampliada do ambiente, visto que estão presentes na atmosfera e, consequentemente, fazem parte do ambiente construído. É válido ressaltar que, na atualidade, o consumo vai além do produto, sendo também imaterial; ou seja, as pessoas consomem a experiência de compra. Dessa forma, o ambiente é percebido pelo consumidor não somente pelas imagens, texturas e sons, mas também pelo odor, o qual possibilita uma experiência mais imersiva ao ambiente.

Apesar de essas questões supracitadas já serem de conhecimento dos profissionais do marketing, de forma geral, arquitetos e designers não têm privilegiado os odores durante a concepção projetual, revelando uma atitude pouco holística frente ao ambiente construído.

Visto isso, é possível destacar que os odores introduzidos nos PDV podem se caracterizar como um diferencial, contribuindo para a explicitação do DNA de uma marca no ambiente construído. Esse é o objetivo dos odores de assinatura: ampliar as experiências e estabelecer vínculos memoráveis. A partir do momento em que o 
cliente é imerso no DNA da marca através do odor, o qual está diretamente relacionado às emoções, esta torna-se memorável. Assim, a dimensão olfativa do projeto de interiores comerciais, quando congruente com os outros elementos da marca, pode, por meio do espaço projetado, proporcionar uma experiência ampliada ao consumidor.

\section{Agradecimentos}

Os autores agradecem à Universidade Federal de Juiz de Fora, especialmente à Pró-Reitoria de Pós-Graduação e Pesquisa (PROPP), pelo suporte à pesquisa. Os agradecimentos também são direcionados à Fundação de Amparo à Pesquisa do Estado de Minas Gerais - Fapemig e ao Conselho Nacional de Desenvolvimento Científico e Tecnológico (CNPq), pela concessão das bolsas de mestrado e de iniciação científica que possibilitaram o desenvolvimento de parte da pesquisa cujos resultados estão apresentados neste artigo.

\section{Referências}

BARBOZA, Maruza Vieira et al. Impacto do Aroma sobre a Percepção da Qualidade no Varejo: experimento em ambiente real de loja: experimento em ambiente real de loja. In: IV ENCONTRO DE MARKETING DA ANPAD, 4., 2010, Florianópolis. Anais [...]. Florianópolis: Ema Anpad, 2010. p. 1-16.

CANNIFORD, Robin; RIACH, Kathleen; HILL, Tim. Nosenography: How smell constitutes meaning, identity and temporal experience in spatial assemblages. Marketing Theory, v. 18 n. 2, p. 234-248, 2017.

CHEBAT, Jean-Charles; MICHON, Richard. Journal of Business Research, v. 56, p. 529- 539, 2003.

CHEIRO BOM LOJA. Perfume sua casa com cheiro de lojas famosas. 2016. Disponível em: http://cheirobomloja.com.br/blog/perfume-sua-casa-com-o-cheiro-de-loja-famosa/. Acesso em: 4 maio 2020.

DIAS, Kadu. Le Lis Blanc. In: Mundo das Marcas, 2017. Disponível em: http://mundodasmarcas.blogspot.com/2017/01/le-lis-blanc.html. Acesso em: abr. 2020.

DIAS, Kadu. Osklen. In: Mundo das Marcas, 2006. Disponível em: http://mundodasmarcas.blogspot.com/2006/06/osklen-brazilian-soul.html. Acesso em: abr. 2020.

EXAME. Para conquistar clientes, marcas investem em "cheirinho de loja": marketing. $\quad$ Marketing. $2017 . \quad$ Disponível em: https://exame.com/marketing/para-conquistar-clientes-marcas-investem-em-cheirinh o-de-lojal. Acesso em: 1 maio 2020. 
FARFETCH. Sobre a marca Osklen: tendências \& subculturas. Tendências \& Subculturas. $2018 . \quad$ Disponível em: https://www.farfetch.com/br/style-guide/tendencias-subculturas/sobre-a-marca-oskle n/. Acesso em: 1 maio 2020.

FLÔR, Priscilla Paoli; UMEDA, Guilherme Mirage. O marketing olfativo como aplicação do marketing experimental: uso de aromatizantes no varejo. In: CONGRESSO DE CIÊNCIAS DA COMUNICAÇÃO NA REGIÃO SUDESTE, 13, 2008, São Paulo. Proceeding [...]. São Paulo: Intercom - Sociedade Brasileira de Estudos Interdisciplinares da Comunicação, 2008, p. 1-15.

FREEPIK. Disponível em: https://br.freepik.com/. Acesso em: mai. 2020.

GIRÃO, Eduardo. Osklen: História da Osklen. 2011. Disponível em: http://eduardogirao.blogspot.com/2011/05/osklen.html. Acesso em: mai. 2020.

GUIMARÃES, Maria. Os mistérios do cheiro. Revista Pesquisa Fapesp, São Paulo, v. 155, p. 16-21, jan. 2009.

GULAS, Charles S.; BLOCH, Peter H. Right under our noses: ambient scent and consumer responses. Journal of Business and Psychology, v. 10, n. 1, p. 87-98, 1995.

HENSHAW, Victoria; MEDWAY, Dominic; WARNABY, Gary; PERKINS, Chris. Marketing the 'city of smells'. Marketing Theory, v. 16, n. 2, p. 153-170, 2015.

KOTLER, Philip. Atmospherics as a Marketing tool. Journal of Retailing, v. 49, n. 4, p. 48-64, jan. 1974.

LAVINIA, Maria. Maria Lavinia Arquitetura: comercial. [s.d.] Disponível em: https://www.marialavinia.com.br/comercial. Acesso em: mai. 2020.

LEENDERS, Mark A.A.M.; SMIDTS, Ale; HAJI, Anouar El. Ambient scent as a mood inducer in supermarkets: The role of scent intensity and time-pressure of shoppers. Journal of Retailing and Consumer Services, v. 48, p. 270-280, 2016.

LINDSTROM, Martin. Brandsense: a marca multissensorial. Porto Alegre: Bookman, 2007. LE LIS BLANC. 2017. (Website). Disponível em: http://mundodasmarcas.blogspot.com/2017/01/le-lis-blanc.html. Acesso em: 4 mai. 2020.

MALHOTRA, Naresh. Design de loja e merchandising visual: criando um ambiente que convida a comprar. São Paulo: Saraiva, 2013.

MALNIC, Bettina. O cheiro das coisas: o sentido do olfato, paladar, emoções e comportamentos. Rio de Janeiro: Vieira \& Lent, 2008.

MARQUES, Fernanda. Fernanda Marques Arquitetos Associados: comercial. [s.d.] Disponível em: https://www.fernandamarques.com.br/le-lis-blanc-shopping-cidade-jardim. Acesso em: mai. 2020. 
MEDINA, Tatiana Lopes. O consumidor e a loja. In: Colóquio [Inter] Nacional CinCCi Sobre Comércio e Cidade: uma relação de origem, 3., Londrina, 2009. Anais do $3^{\circ}$ Colóquio [Inter] Nacional CinCCi Sobre Comércio e Cidade: uma relação de origem. Londrina: PUC-PR - Pontifícia Universidade Católica do Paraná, 2009.

MORRIN, Maureen; KRISHNA, Aradhna; LWIN, May O. Is scent-enhanced memory immune to retroactive interference? Journal of Consumer Psychology, v. 21, p. 354-361, 2011.

OKAMOTO, Jun. Percepção ambiental e comportamento: visão holística da percepção ambiental na arquitetura e na comunicação. São Paulo: Editora Mackenzie, 2002.

PALLASMAA, Juhani. Os olhos da pele: a arquitetura e os sentidos. Porto Alegre: Bookman, 2011.

PINE, Joseph; GILMORE, James H. Welcome to the experience economy. Harvard Business Review. v.76, n. 4, jul. / ago. 1998.

RHEINGANTZ, Paulo A. Centro empresarial internacional Rio: análise pós-ocupação, por observação participante, das condições internas de conforto. 1995. Dissertação (Mestrado em Arquitetura) - FAU/UFRJ, Rio de Janeiro, 1995.

ROMANOS, Paloma Almeida. Conforto olfativo e o projeto de interiores comerciais. Juiz de Fora, 2020. 140f. Dissertação (mestrado acadêmico) Universidade Federal de Juiz de Fora, Faculdade de Engenharia. Programa de Pós-Graduação em Ambiente Construído.

ROMANOS, Paloma Almeida; BRAIDA, Frederico; MONKEN, Isabela; MENDES, Caroliny. O cheiro no projeto de interiores comerciais. Revista Ergodesign HCI, [S.I.], v. 7, n. 1, p. 27-40, jan. 2020.

SADDI, Monica Saboia. Design do PDV: interdisciplinaridade, novos conceitos e objetivos nos projetos de arquitetura e design para o varejo de moda. Rio de Janeiro, 2013. 298f. Tese de Doutorado, Departamento de Artes e Design, Pontifícia Universidade Católica do Rio de Janeiro.

SEIVAROMA. Revista Le Lis. $2017 . \quad$ Disponível em: http://www.seivaroma.com.br/team-view/revista-le-lis/. Acesso em: 1 maio 2020.

SHOPPING LEBLON. Lojas/Osklen. 2000 Disponível em: https://shoppingleblon.com.br/lojas/osklen.htm. Acesso em: abr. 2020.

SPANGENBERG, Eric R.; SPROTT, David E.; GROHMANN, Bianca; TRACY, Daniel L. Gender-congruent ambient scent influences on approach and avoidance behaviors in a retail store. Journal of Business Research, v. 59, p. 1281-1287, 2006.

VELLOSO, Isabela Monken. Design olfativo e brasilidade: os encantos da experiência. In: BELCHIOR, Camilo; BOAS, Pâmilla Vilas; ULHÔA, Ana Claudia; VALENTIN, Cláudio; MAIA, Marcos; IMPELIZIERI, Cilene (org.). Revista ideia design: fora do eixo. v. 4. Belo Horizonte: Editora Plexudesign, 2019. p. 85-89. 